\title{
A TEMÁTICA SUSTENTABILIDADE NA FORMAÇÃO EM ADMINISTRAÇÃO: A INFLUÊNCIA DE ELEMENTOS CONTEXTUAIS, ORGANIZACIONAIS E CURRICULARES
}

\author{
SUSTAINABILITY IN MANAGEMENT EDUCATION: THE INFLUENCE OF
}

CONTEXTUAL, ORGANIZATIONAL AND CURRICULAR ELEMENTS

Recebido em: 29/03/2019 - Aprovado em: 10/08/2019

Avaliado pelo sistema double blind review

Editora Científica convidada: Patricia Kanashiro DOI 10.13058/raep.2019.v20n3.1482

\section{PAOLASCHMITT FIGUEIRÓ paolaadm@gmail.com GUILHERME FROZZA FELIX DA SILVA ARIANA RAQUEL PHILERENO}

\author{
Universidade FeEvale
}

\begin{abstract}
RESUMO
Este artigo traz a educação superior como elemento-chave para promover ação e mudanças. O enfoque é a formação de gestores partindo do pressuposto de que as organizações e seus atores são essenciais para promover impactos positivos na sociedade. Nesse contexto, este artigo propõe-se a responder ao seguinte questionamento: de que maneira elementos contextuais, organizacionais e curriculares podem colaborar para a presença da temática sustentabilidade na formação superior em Administração? Assim, o objetivo geral envolveu analisar em que medida elementos contextuais, organizacionais e curriculares colaboram para a formação superior em Administração sob a perspectiva da sustentabilidade. Para tanto, foi realizado um estudo de caso de cunho qualitativo em uma universidade privada do Rio Grande do Sul. A coleta de dados foi dividida em quatro etapas, considerando: análise detalhada dos planos de ensino das disciplinas, realização de entrevistas com atores-chave na gestão da instituição, grupo focal com estudantes, aplicação de questionário a estudantes dos últimos semestres do curso e dados secundários presentes no site institucional e em documentos internos da instituição. Os principais resultados mostram que existe um movimento institucional que emerge principalmente da característica comunitária da Universidade e das avaliações externas. Existem práticas socioambientais, mas a IES é percebida mais sob a perspectiva da inovação e não da sustentabilidade. O currículo da Administração sofreu mudanças que incluem a inserção de disciplinas específicas das áreas, o que vai ao encontro da demanda manifestada pelos estudantes.
\end{abstract}

Palavras-chave: Educação para a sustentabilidade. Ensino superior. Administração.

\begin{abstract}
This paper considers Higher Education as a key element to encourage actions and changes. It emphasizes the education of managers. This is based on the supposition that organizations and their actors are essential in promoting positive outcomes in society. In this context, this paper proposes to answer the following question: How can contextual, organizational and curricular elements collaborate to the topic of Sustainability in Management Education? Thus, the aim of this paper is to analyze to what extent context, organizational and curricular elements collaborate for the Management Education from the Sustainability perspective. Therefore, to achieve this a case study was carried out at a private university in Rio Grande do Sul, Brazil. The data collection was divided into four phases: analysis of Administration course Syllabus; interview with the key people in the institution's administration; focus group with students; application of a questionary to students. Besides, secondary data from the institutional website and documents of the institution were considered. The main results show there is an institutional movement that emerges from the communitary characteristics of Higher Education Institution (HEI) and from external evaluations. There are also socioenvironmental practices, but the HEI is usually viewed as a means of innovation and not necessarily as a means of sustainability. The Business Administration curriculum went through changes that include the insertion of specific courses in these areas, which coincide to the concern expressed by the students.
\end{abstract}

Keywords: Education for Sustainability. Higher Education. Management. Business Administration. 


\section{INTRODUÇÃO}

Apesar da redução nas taxas de fertilidade em alguns países, a população mundial soma, atualmente, em torno de 7,6 bilhões de pessoas, mas esse número pode chegar a 9,8 bilhões em 2015 (ONU, 2017). Nesse cenário, há de se considerar o impacto da vida humana na Terra e de toda a infraestrutura necessária para suportar tamanho volume, além da minimização dos impactos negativos já causados pela "evolução". É cada vez mais urgente investir em planejamento e inovações que tratem da sustentabilidade e, portanto, do entrelaçamento entre aspectos ambientais, sociais e econômicos. Envolve abordar temas como saneamento, educação, assistência médica, vulnerabilidade social, mobilidade urbana, desmatamento, poluição, segurança, inclusão, empregabilidade, refugiados, entre tantos outros. São numerosas e urgentes as demandas, mas o intuito não é enumerá-las neste momento, o que se pretende é chamar a atenção para a necessidade de ação.

É nesse cenário que este artigo se apresenta, trazendo especificamente a educação superior como elemento-chave para promover ação e mudança. Parte-se do pressuposto de que as organizações, seus gestores e demais atores envolvidos nos processos de tomada de decisão são essenciais para a promoção de mudanças positivas, seja com impactos em nível micro e/ou em nível macro. No entanto, o maior desafio recai sobre os padrões existentes. A mentalidade cujo foco se resume no lucro a qualquer custo foi (e ainda é) o mainstream de muitas organizações e do ensino na área, o que torna ainda mais desafiador e tortuoso o caminho em direção a uma visão que contemple a sustentabilidade nos processos de tomada de decisão.

Empresas sustentáveis possuem maior vantagem competitiva, pois reconhecem que a consciência de seus atos e os impactos deles na sociedade ou na natureza podem ser a chave para a geração de valor em longo prazo (TERCEK; ADAMS, 2014). Esse olhar vem ganhando espaço, mesmo que a passos lentos. Ainda se faz necessário reinstitucionalizar modelos, normas, mitos e valores que hoje já não atendem aos anseios da sociedade [e do Planeta] (MUCK; SOUZA; ZAGUI, 2012). São necessárias mudanças culturais nas estruturas organizacionais e também nas instituições de ensi- 
no. Os pressupostos da sustentabilidade precisam ser discutidos em todos os níveis de ensino, a fim de despertar criticidade, sensibilidade e empatia, associados aos conhecimentos técnicos já presentes nas bases curriculares.

Com o fim da Década Internacional da Educação para o Desenvolvimento Sustentável (2005 - 2014), promovida pela UNESCO, o tema ganha nova força e visibilidade com a Agenda 2030 para o Desenvolvimento Sustentável, que propõe 17 Objetivos de Desenvolvimento Sustentável (ODS) e um total de 169 metas (ONU, 2015), que, em sua maioria, envolvem consequências diretas ou indiretas decorrentes de processos educacionais. A educação é importante para todos os 17 objetivos, considerando que a sustentabilidade representa um desafio educacional para a humanidade, com ênfase maior no [processo de] aprendizagem do que no ensino em si (BELL, 2016). Ainda nesse contexto, ressalta-se que uma importante iniciativa que nasceu com a Década da UNESCO é o programa Teaching and Learning for a Sustainable Future, que oferece desenvolvimento profissional para atuais e futuros professores e demais profissionais da área da educação ao redor do mundo (UNESCO, 2019).

O documento final da Conferência das Nações Unidas sobre Desenvolvimento Sustentável (Rio+20), realizada em 2012, recomendou que as instituições de ensino adotassem boas práticas de gestão ambiental, contando com ativa participação de estudantes, professores e parceiros locais, bem como que sejam ministrados conteúdos sobre a temática nas diversas disciplinas, a partir de uma abordagem curricular integrada e transversal. No Brasil, uma das iniciativas foi o estabelecimento das Diretrizes Curriculares Nacionais para a Educação Ambiental, em nível básico e superior, por meio de Resolução do Conselho Nacional de Educação CNE (MEC, 2012). Atualmente, a Educação Ambiental está explícita em um dos indicares de avaliação dos cursos de graduação, presenciais ou à distância (INEP, 2019b).

Com ênfase na área de Administração, destaca-se o Principles for Responsible Management Education (PRME), que tem como objetivo a melhoria contínua das instituições de ensino com o foco de preparar a nova geração de gestores para serem capazes de gerenciar grandes desafios en- 
contrados no Século XXI. No Brasil, atualmente, são 28 instituições cadastradas (PRME, 2018). No âmbito acadêmico, considerando as pesquisas em Administração, o espaço e o interesse também ganham cada vez mais força e legitimidade, com chamadas especiais em revistas e o lançamento de livros. Outro indicativo é que foi incluído, recentemente, o tema "Educação para a Sustentabilidade na Administração e Contabilidade" na divisão acadêmica de Ensino e Pesquisa da ANPAD (Associação Nacional de Pós-Graduação e Pesquisa em Administração).

Sobre os cursos de Administração no Brasil, os dados mais recentes indicam que, considerando a modalidade presencial e à distância, existem 4.945 Instituições de Ensino Superior (IES), 654 públicas e 4.291 privadas. Somente no ano de 2016, levando em conta as diferentes ênfases ligadas à gestão, foram aproximadamente 240.750 alunos concluintes (INEP, 2017). Esses números demonstram a importância e o impacto que pode ser gerado ao aproximar a sustentabilidade das escolas de negócios.

Diante do exposto, a presente pesquisa buscou responder ao seguinte questionamento: de que maneira elementos contextuais, organizacionais e curriculares podem colaborar para a presença da temática sustentabilidade na formação superior em Administração? Assim, o objetivo geral buscou analisar em que medida elementos contextuais, organizacionais e curriculares colaboram para formação superior em Administração sob a perspectiva da sustentabilidade. Para tanto, foi realizado um estudo de caso em uma universidade privada situada no Rio Grande do Sul, com abordagem qualitativa e coleta de dados dividida em quatro etapas: (i) análise dos planos de ensino das disciplinas do curso de Administração; (ii) realização de entrevistas com atores-chave na gestão da instituição; (iii) aplicação de questionário a estudantes matriculados nos últimos semestres; e (iv) grupo focal realizado com estudantes em final de curso. De forma complementar, foram acessadas informações no site institucional e consultados documentos internos disponibilizados pela instituição. Para a análise dos dados, foi utilizada a técnica de análise de conteúdo. A seguir, tem-se o referencial teórico, base para a coleta e análise dos dados, seguido dos procedimentos metodológicos, da análise e discussão dos resultados e das considerações finais. 


\section{EDUCAÇÃO PARA A SUSTENTABILIDADE E A FORMAÇÃO EM AD- MINISTRAÇÃO}

As alterações na sociedade ao longo do tempo resultam do sistema econômico que a rege. A modernidade modificou a sociedade e acabou trazendo à tona a necessidade de uma boa interação entre o homem e o meio que o ampara, trazendo um significado completamente distinto para a vida social (MUNCK; SOUZA; ZAGUI, 2012). Nesse cenário, com a percepção do esgotamento dos recursos naturais, por exemplo, houve também a necessidade de as organizações repensarem suas posturas de desenvolvimento "a qualquer custo" e, desde então, tem-se percebido o aumento de uma postura um pouco mais sensível e dinâmica quanto às mudanças (KUZMA et al., 2016).

Há uma necessidade urgente de abordar os desafios ligados à sustentabilidade e explorar novas formas de operar, pesquisar e também inovar, permitindo que a sociedade seja capaz de responder a esses desafios (TASSONE et al., 2018). O ensino superior, nesta pesquisa, com enfoque na área de Administração, deve acompanhar esse processo de mudança. Mas, desde o início dos estudos formais sobre a graduação em Administração, datado de 1881, na Pensilvânia (primeiro curso de Administração formal), os ensinamentos sobre como gerir uma empresa baseiam-se na lucratividade e rentabilidade. No Brasil, segundo Alves (2016), os estudos do curso de Administração iniciaram-se em 1940, em um período pós Segunda Guerra Mundial e, por essa razão, o objetivo principal era a busca pela reestruturação da economia, o progresso e a intensificação da produção, sem considerar os impactos negativos gerados. Esse foi o padrão que norteou toda a dinâmica do ensino da gestão.

No entanto, buscar um mundo mais sustentável requer a transformação dos valores éticos e morais da sociedade e das organizações. Entende-se que essa mudança de padrões só é possível por meio da educação, fazendo dela um instrumento para tratar aspectos ambientais e sociais (PETARNELLA; SILVEIRA; MACHADO, 2017; PIDLISNYUK, 2010; GADOTTI, 2008). Obviamente, a educação não deve ser vista como uma "panaceia" 
que resolverá todos os problemas éticos existentes no mundo, mas pode se tornar um espaço para orientação, interação e experiências que produzam mudanças cognitivas e afetivas nos indivíduos (SETÓ-PAMIES; PAPAOIKONOMOU, 2016).

Atualmente, a preocupação com o meio ambiente e com questões sociais está presente, inclusive, na legislação educacional brasileira - Diretrizes Curriculares Nacionais de Educação Ambiental (MEC, 2012). No entanto, um ponto destacado por Petarnella, Silveira e Machado (2017) é que políticas que integrem a educação e a sustentabilidade são quase nulas e há pouca legislação rigorosa e, portanto, efetiva sobre o tema. No Brasil, em 2004, foi criado o SINAES (Sistema Nacional de Avaliação da Educação Superior) com o objetivo de analisar as instituições, os cursos e o desempenho dos estudantes, avaliando todos os aspectos que giram em torno desses eixos, tais como: ensino, pesquisa, extensão, responsabilidade social, desempenho dos alunos, gestão da instituição, corpo docente, instalações. O SINAES reúne informações do Exame Nacional de Desempenho de Estudantes (ENADE) e das avaliações institucionais e dos cursos (INEP, 2019a).

É relevante considerar o SINAES nesta discussão, tendo em vista que uma das dimensões levadas em conta na avaliação institucional é a responsabilidade social das IES. Outro motivo é que a avaliação dos estudantes é realizada via ENADE, cujo principal objetivo é avaliar o desempenho dos alunos em relação às competências desenvolvidas ao longo da formação. Assim, as questões da prova representam um indicativo do tipo de formação que está sendo observada (INEP, 2019a). Já quanto à avaliação dos cursos de graduação, tanto para reconhecimento do curso quanto para a renovação, é utilizado um instrumento que contempla três dimensões: organização didático-pedagógica, corpo docente e tutorial e infraestrutura (INEP, 2019b).

A primeira dimensão é a que considera mais elementos relacionados (direta ou indiretamente) à presença da sustentabilidade no ensino. Essa dimensão apresenta indicadores de adequação das práticas didático-pedagógicas de ensino, pesquisa e extensão ao perfil profissional do egresso 
constante no Projeto Pedagógico do Curso (PPC). Em um dos indicadores, é dada atenção justamente a um perfil profissional que leva em consideração competências alinhadas às novas demandas apresentadas pelo mundo do trabalho (INEP, 2019b), o que pode estar intrinsecamente relacionado a questões sociais e ambientais. Alinhado a isso, o indicador de avaliação, chamado "conteúdos curriculares", tem relação direta com a sustentabilidade, pois considera para uma pontuação máxima

os conteúdos curriculares, constantes no PPC, promovem o efetivo desenvolvimento do perfil profissional do egresso, considerando a atualização da área, $[. .$.$] a abordagem de conteúdos pertinentes às políticas de$ educação ambiental, de educação em direitos humanos e de educação das relações étnico-raciais e o ensino de história e cultura afro-brasileira, africana e indígena, diferenciam o curso dentro da área profissional e induzem o contato com conhecimento recente e inovador (INEP, 2019b, p.11, grifo nosso).

Nessa perspectiva, Pontes et al. (2015) reforçam que, embora a sustentabilidade já esteja inserida no contexto de algumas organizações educacionais, seja nos currículos ou nas demais práticas de gestão, sua presença necessita de expansão. Além disso, o que se questiona é a maneira como tal inserção está sendo conduzida. Ainda que seja notável o esforço para ampliar a presença da sustentabilidade em discussões e movimentos sociais e educacionais, muitos gestores acreditam não estar preparados para tratar assuntos sociais e ambientais dentro das organizações. Esse problema pode estar ligado ao fato de que hoje o tema ainda seja trabalhado de forma "superficial" no ensino (FIGUEIRÓ, 2015; SHARMA; HART, 2014; CARVALHO; BRUNSTEIN; GODOY, 2014), desconsiderando a importância de um processo de ensino e aprendizagem crítico e reflexivo (LESSA; SPIER; NASCIMENTO, 2018; BRUNSTEIN; SAMBIASE; BRUNNQUELL, 2018) e, muitas vezes, compreendido apenas sob a perspectiva ambiental (técnica) ou mero cumprimento de legislação (DEMAJOROVIC; SILVA, 2012; RICHTER; SCHUMACHER, 2011; BENN; DUNPHY, 2009). 
É importante ressaltar que, no âmbito da gestão, a sustentabilidade assume "um caráter estratégico, que empreende a formação de uma visão de sociedade e de mundo numa perspectiva de longo prazo" (KUZMA et al., 2016, p.152). Assim, incorporar a sustentabilidade às práticas de negócios é bastante complexo e desafiador. Nesse sentido, Petrini e Pozzebon (2010) propõem um modelo conceitual que evidencia diversos fatores determinantes para esse processo e que envolve uma interconexão de categorias, incluindo a visão, a estrutura e mecanismos organizacionais. Nessa linha de raciocínio, na perspectiva de Marcon e Sorinao-Sierra (2017), a adoção de posturas sustentáveis por parte das organizações pressupõe uma mudança cultural para que, inclusive, o desenvolvimento sustentável passe a integrar a estratégia corporativa. Parte-se, assim, do pressuposto de que as organizações necessitam de profissionais cujos conhecimentos e habilidades permitam um olhar sistêmico e capaz de articular, até mesmo, uma mudança de cultura organizacional visando à inserção da sustentabilidade em suas práticas.

Para tanto, o contexto em que está inserida a comunidade acadêmica exerce considerável influência sobre suas práticas (ENGLUND; OLOFSSON; PRICE, 2018). Na medida em que as instituições de ensino e seus docentes começarem a repensar seus papéis como agentes de mudança, será possível a inclusão do tema na educação e, assim, levá-lo para as organizações (BRUNSTEIN; GODOY; SILVA, 2014). No entanto, "conciliar os princípios de desenvolvimento sustentável com as práticas de gestão educacional é um desafio, já que requer a conscientização e o comprometimento de todos os atores envolvidos no processo" (PONTES et al., 2015, p.85). Além disso, deve-se considerar também a importância da avaliação das práticas, analisando o que funciona e o que não funciona, bem como as razões para tal e em qual contexto estão inseridas (KOEHN; UITTO, 2014).

Mas, apesar das dificuldades, sejam elas de ordem organizacional, pedagógica, conceitual e, até mesmo, comportamentais (FIGUEIRÓ; NASCIMENTO, 2018; FIGUEIRÓ; RAUFFLET, 2015; KURUCZ; COLBERT; MARCUS, 2013; THOMAS; HERGARTY; HOLDSWORTH, 2012), algumas instituições de ensino superior brasileiras apresentam iniciativas que 
refletem certa preocupação com a formação dos futuros gestores (FRANCO et al., 2015; SCHUTEL, 2015; PALMA; ALVES; SILVA, 2013). No entanto, a iniciativa bem como a sua continuidade, muitas vezes, depende de poucos atores, geralmente docentes, cujo perfil e cuja formação acadêmica contribuem para seu interesse pelo tema e para o consequente estímulo no curso e na instituição. É nessa dependência que reside um dos principais desafios da relação entre a educação e a sustentabilidade, já que muitos docentes podem não se sentir aptos para trabalharem com o tema, além de ele estar diretamente relacionado ao seu esforço pessoal para que a prática aconteça (RICHTER; SCHUMACHER, 2011; DAVIS et al., 2003). Os profissionais educadores nem sempre estão preparados para mostrar aos novos gestores como devem agir nesse novo mercado em constante transformação e, com isso, o tema continua, muitas vezes, subjugado.

Por fim, outro ponto que merece destaque são os processos de ensino e aprendizagem que circundam a sustentabilidade em todas as suas esferas. O respeito à vida, ao meio ambiente, às pessoas, às futuras gerações e ao planeta não é possível de ser ensinado apenas de maneira passiva nas salas de aula. Tem-se o dever de estimular processos de aprendizagem que envolvam os indivíduos e os façam refletir sobre suas ações e decisões, tendo a compreensão acerca da vida em sociedade (FIGUEIRÓ, 2015). Esse desafio ganha força na medida em que, uma vez que já está incorporada uma determinada visão de mundo associada a seres egoístas, lucrativos e oportunistas (visão neoclássica), eles estariam mais inclinados a entender e aprender tópicos confirmando essas crenças (LESSA; SPIER; NASCIMENTO, 2018). Assim, é imperativo que ensinar a temática sustentabilidade exige uma mudança de uma tradicional abordagem centrada no professor para uma abordagem centrada no aluno (ERSKINE; JOHNSON, 2012; RICHTER; SCHUMACHER, 2011).

Um processo mais dinâmico de aprendizagem pode ser alcançado de diferentes formas. As estratégias mais frequentes na literatura são: (1) Casos; (2) Aprendizagem Baseada em Projetos (Project-Based Learning), (3) Aprendizagem Baseada em Problemas (Problem-Based Learning), (4) Aprendizagem Experiencial (Experiential Learning); (5) Service Learning, 
(6) Aprendizagem Social, e (7) Aprendizagem Situada. O denominador comum dessas estratégias é que promovem, em diferentes graus, a mudança de um currículo centrado no conteúdo para um mais centrado nos estudantes, visando formar cidadãos responsáveis e promover o desenvolvimento de habilidades como a resolução de problemas e o pensamento crítico (ANDERBERG et al., 2009).

Nesse aspecto, ressalta-se a importância da formalização de projetos de extensão nas IES (BROSTRÖM; FELDMANN; KAULIO, 2019), incentivando a aprendizagem gerada fora da sala de aula (SETÓ-PAMIES; PAPAOIKONOMOU, 2016). Em outras palavras, é o chamado Service Learning (SL), cuja aprendizagem é gerada a partir da participação ativa dos estudantes em serviços geralmente voltados à comunidade (CNCS, 2017). O SL vem ganhando popularidade nas escolas de negócios ao complementar as abordagens tradicionais, pois é capaz de capturar dimensões de responsabilidade social enquanto reforça a aprendizagem acadêmica (YORIO; YE, 2012). 


\section{ASPECTOS-CHAVE PARA A INTEGRAÇÃO DA SUSTENTABILIDA- DE AO ENSINO}

Pode-se dizer que os desafios mencionados ao longo deste referencial integram a relação de interdependência apresentada por Kurucz, Colbert e Marcus (2013) entre quatro dimensões operacionais da educação em gestão - contextual, organizacional, curricular e pedagógica. A dimensão contextual incide sobre os sistemas de educação em Administração e as normas culturais que dão suporte à sua existência. A dimensão organizacional das IES inclui o estilo de gestão e a estrutura de governança presentes. Já a dimensão curricular envolve o conteúdo e o design do programa e das disciplinas. Por fim, a dimensão pedagógica tem seu enfoque nos métodos de ensino aplicados em sala de aula (KURUCZ; COLBERT; MARCUS, 2013).

Partindo dessa perspectiva e levando em consideração outros estudos que discutem essas dimensões ou níveis de análise acerca da presença da temática sustentabilidade no ensino da gestão (SETÓ-PAMIES; PAPAOIKONOMOU, 2016; FIGUEIRÓ; RAUFFLET, 2015; JABBOUR, 2010), Figueiró (2015) propôs e validou uma estrutura analítica envolvendo 58 elementos distribuídos em diferentes categorias, conforme configuração e descrição presentes no Quadro 1.

Quadro 1 Categorias e elementos de análise nas dimensões contextual, organizacional, curricular e pedagógica

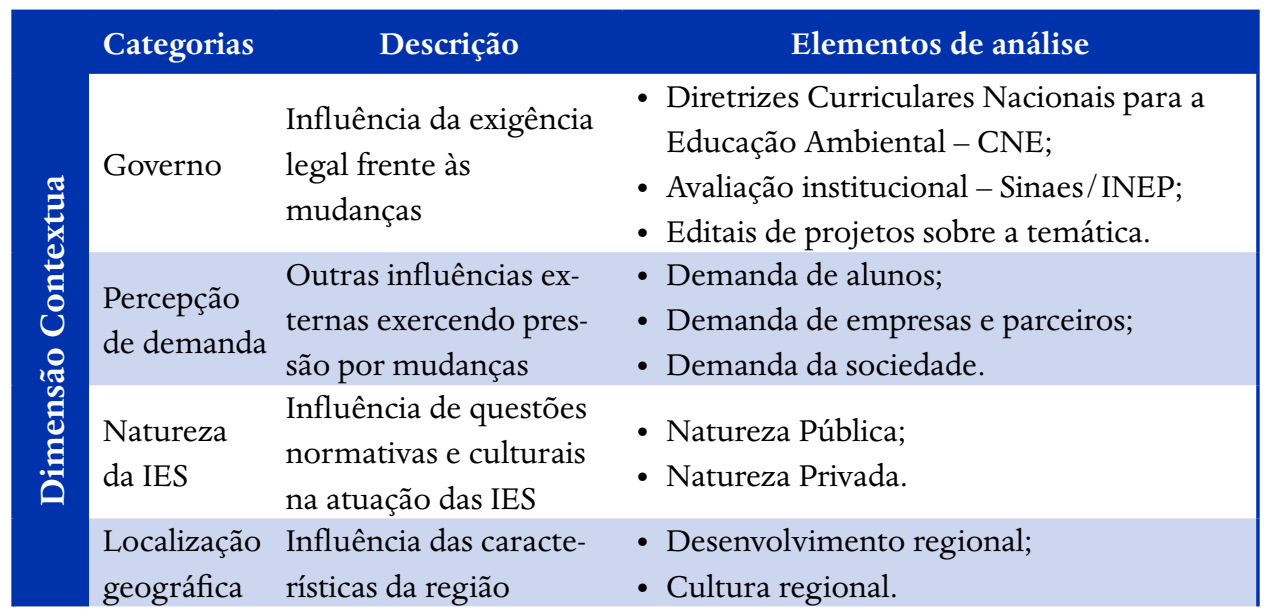




\begin{tabular}{|c|c|c|}
\hline $\begin{array}{l}\text { Estrutura } \\
\text { organiza- } \\
\text { cional }\end{array}$ & $\begin{array}{l}\text { Perfil e planejamento } \\
\text { organizacional }\end{array}$ & $\begin{array}{l}\text { - Rotinas administrativas; } \\
\text { - Comunicação interna; } \\
\text { - Incentivo à interação ente departamentos; } \\
\text { - Rotatividade; } \\
\text { - Estabilidade no cargo; } \\
\text { - Predisposição para inovar. }\end{array}$ \\
\hline & $\begin{array}{l}\text { Sistema de Gestão Am- } \\
\text { biental: se a existência } \\
\text { de rotinas ligadas à } \\
\text { sustentabilidade interfe- } \\
\text { re no ensino }\end{array}$ & $\begin{array}{l}\text { - Oferta de cursos para a comunidade } \\
\text { acadêmica; } \\
\text { - Práticas de Reuso; } \\
\text { - Práticas de Reciclagem; } \\
\text { - Práticas de Redução. }\end{array}$ \\
\hline $\begin{array}{l}\text { Desafios de } \\
\text { suporte }\end{array}$ & $\begin{array}{l}\text { Incentivo da instituição } \\
\text { frente às mudanças }\end{array}$ & $\begin{array}{l}\text { - Exigência top-down; } \\
\text { - Compromisso da instituição; } \\
\text { - Liberação de recursos financeiros; } \\
\text { - Oferta de formação continuada; } \\
\text { - Indicadores de desempenho; } \\
\text { - Papel da coordenação do curso. }\end{array}$ \\
\hline $\begin{array}{l}\text { Desafios } \\
\text { comporta- } \\
\text { mentais }\end{array}$ & $\begin{array}{l}\text { Motivadores e obstá- } \\
\text { culos de ordem pessoal } \\
\text { para a realização das } \\
\text { mudanças }\end{array}$ & $\begin{array}{l}\text { - Comprometimento; } \\
\text { - Interesse pelo tema; } \\
\text { - Interesse e participação em projetos sobre } \\
\text { o tema; } \\
\text { - Resistência à mudança; } \\
\text { - Confiança para ensinar; } \\
\text { - Tempo e esforço (extras). }\end{array}$ \\
\hline $\begin{array}{l}\text { Natureza } \\
\text { da disci- } \\
\text { plina }\end{array}$ & $\begin{array}{l}\text { Caso exista, como a(s) } \\
\text { disciplina(s) é(são) ofer- } \\
\text { tada aos alunos }\end{array}$ & $\begin{array}{l}\text { - Disciplina de caráter obrigatório; } \\
\text { - Disciplina de caráter eletivo. }\end{array}$ \\
\hline $\begin{array}{l}\text { Presença } \\
\text { no currí- } \\
\text { culo }\end{array}$ & $\begin{array}{l}\text { Como a temática sus- } \\
\text { tentabilidade está pre- } \\
\text { sente no currículo }\end{array}$ & $\begin{array}{l}\text { - Disciplinar (disciplina isolada); } \\
\text { - Cross-disciplinar (transversal); } \\
\text { - Interdisciplinar; } \\
\text { - Multidisciplinar; } \\
\text { - Transdisciplinar. }\end{array}$ \\
\hline Extensão & $\begin{array}{l}\text { Projetos de extensão re- } \\
\text { lacionados com a temá- } \\
\text { tica sustentabilidade }\end{array}$ & $\begin{array}{l}\text { - Parceria com o setor privado; } \\
\text { - Parceria com o setor público; } \\
\text { - Parceria com a sociedade civil. }\end{array}$ \\
\hline Pesquisa & $\begin{array}{l}\text { Presença de linhas de } \\
\text { pesquisa sobre a temáti- } \\
\text { ca sustentabilidade }\end{array}$ & $\begin{array}{l}\text { - Linha de pesquisa direta; } \\
\text { - Linha de pesquisa indireta; } \\
\text { - Grupo de pesquisa. }\end{array}$ \\
\hline
\end{tabular}




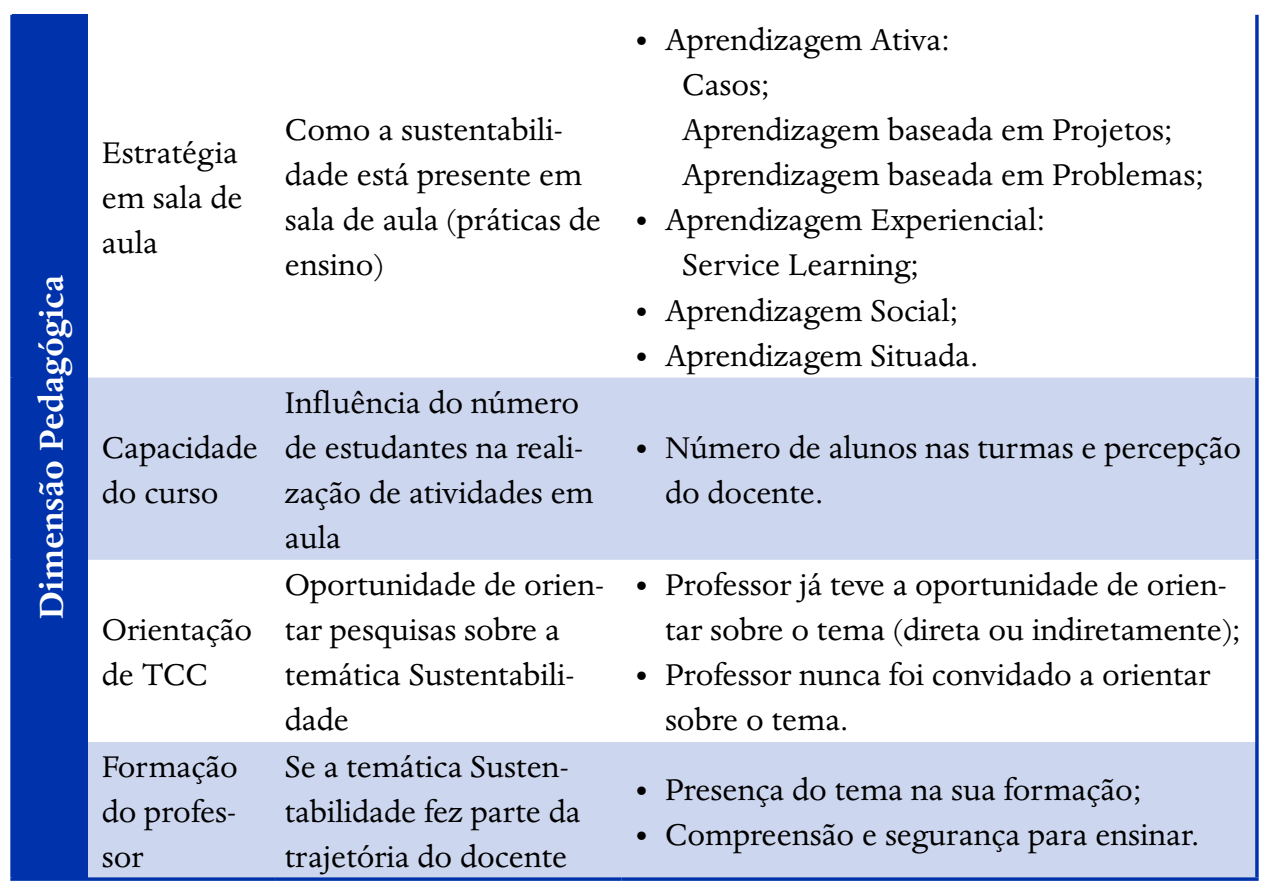

Fonte: Adaptado de Figueiró (2015) e Figueiró e Nascimento (2018).

Parte-se do pressuposto de que ampliar o entendimento acerca desses elementos pode ser um direcionador estratégico para as IES. Vale mencionar que o foco da presente pesquisa, assim como a validação da estrutura analítica aqui considerada, foi a graduação em Administração. No entanto, essa estrutura de análise pode ser adaptada e aplicada a qualquer curso e nível de ensino. Diante do exposto, esta pesquisa pretende servir como pano de fundo para que a presença da temática sustentabilidade seja avaliada e, a partir disso, possa fornecer subsídios para uma efetiva integração nos currículos e práticas das instituições de ensino. A seguir, têm-se os procedimentos metodológicos utilizados para o cumprimento do objetivo traçado. 


\section{PROCEDIMENTOS METODOLÓGICOS}

O objetivo proposto caracteriza a presente pesquisa como descritiva, a partir da realização de um estudo de caso de cunho qualitativo, sob a perspectiva de Yin (2010). A unidade de análise foi constituída pelo Curso de Administração de uma Universidade Privada, localizada na região do Vale do Sinos, Rio Grande do Sul. O planejamento e a execução da coleta de dados ocorreram em quatro etapas, considerando os elementos expostos no Quadro 1.

Assim, na primeira etapa, que teve na ênfase na dimensão curricular, foram analisados os planos de ensino das 75 disciplinas que compõem a grade curricular do curso de Administração, com o objetivo de identificar quais delas abordam a temática sustentabilidade, direta ou indiretamente. Foram consideradas 72 disciplinas, já que três optativas da formação complementar em gestão ainda não foram ofertadas por falta de adesão, são elas: Gestão por Processos, Relações Interorganizacionais e Responsabilidade Social e Ética, esta última com uma relação direta explícita com a temática em análise.

Para o processo de busca na ementa, nos objetivos e nos programas de aprendizagem de cada plano de ensino, foram utilizadas as seguintes palavras-chave: sustentabilidade, desenvolvimento sustentável e socioambiental - social/ambiental. Ressalta-se que, com base na uma leitura cuidadosa dos planos na íntegra, também houve o cuidado de observar a presença de outros termos correlatos, como, por exemplo: natureza, ética, verde, resíduos, reciclagem, logística reversa, consumo consciente, etc.

A segunda etapa contou com a realização de quatro entrevistas a partir de um roteiro semiestruturado específico para cada respondente. Foram entrevistados os seguintes profissionais: pró-reitora de ensino (PE), coordenador administrativo da Comissão Própria de Avaliação (CCPA), engenheira responsável pelo Grupo Interno de Gerenciamento Ambiental (EGA) e coordenação do Curso de Administração (CA). Na análise dos resultados, são utilizadas as siglas mencionadas para se referir a cada um dos entrevistados. 
$\mathrm{Na}$ terceira etapa da coleta de dados, foram aplicados questionários a estudantes regularmente matriculados nos semestres finais $\left(7^{\circ}\right.$ e $\left.8^{\circ}\right)$ do curso de Administração. O questionário foi elaborado considerando o interesse em verificar a percepção dos alunos sobre a presença do tema durante sua formação, bem como se o grupo se sente preparado para atuar ou propor projetos nessa área. Também foram considerados os dados das fases anteriores (planos de ensino e entrevistas) e a validação foi realizada por um pesquisador especialista na área.

Nessa configuração, no momento da coleta de dados, havia um total de 15 turmas, com 457 estudantes. Os questionários foram aplicados presencialmente em nove dessas turmas, de acordo com a disponibilidade dos professores contatados previamente. Vale ressaltar que, nos semestres finais, algumas disciplinas são voltadas à orientação individual de monografias, portanto, as turmas nem sempre contam com a presença de todos os estudantes em sala. Com isso, foram obtidas 144 respostas válidas, cuja tabulação foi realizada no software Excel ${ }^{\circledR}$. A análise foi realizada a partir de estatística descritiva.

A quarta e última etapa envolveu a realização de um grupo focal com 10 estudantes matriculados em final de curso. A duração do encontro foi de 40 minutos. De forma complementar, alguns dados foram obtidos no site institucional e também a partir do Plano de Desenvolvimento Institucional (PDI) da Universidade, do Projeto Político Pedagógico do Curso de Administração e da listagem dos projetos de extensão em andamento. Tais procedimentos levaram a uma pequena redução em relação às categorias iniciais mencionadas no Quadro 1, tendo em vista que nem todos os elementos emergiram na coleta de dados e também porque a dimensão pedagógica não fez parte do escopo da pesquisa. Assim, foi realizada uma análise de conteúdo (BARDIN, 2011), seguindo a categorização apresentada no Quadro 2.

A partir do exposto, a análise foi realizada a partir da triangulação de cinco diferentes fontes de dados: planos de ensino das disciplinas do curso de Administração, entrevistas com atores institucionais, grupo focal, questionário com estudantes e dados secundários. A seguir, tem-se a análise dos resultados obtidos nas etapas descritas. 
Quadro 2 Categorias e elementos de análise considerados na pesquisa

\begin{tabular}{|c|c|c|}
\hline Categorias & Descrição & Elementos de análise \\
\hline Governo & $\begin{array}{l}\text { Influência da exigência } \\
\text { legal frente às mudanças }\end{array}$ & $\begin{array}{l}\text { - Diretrizes Curriculares Nacionais } \\
\text { para a Educação Ambiental - } \\
\text { CNE; } \\
\text { - Avaliação institucional - SI- } \\
\text { NAES/INEP. }\end{array}$ \\
\hline Natureza da IES & $\begin{array}{l}\text { Influência de questões } \\
\text { normativas e culturais na } \\
\text { atuação das IES }\end{array}$ & $\begin{array}{l}\text { - Natureza Pública; } \\
\text { - Natureza Privada. }\end{array}$ \\
\hline $\begin{array}{l}\text { Localização geo- } \\
\text { gráfica }\end{array}$ & $\begin{array}{l}\text { Influência das característi- } \\
\text { cas da região }\end{array}$ & $\begin{array}{l}\text { - Desenvolvimento regional; } \\
\text { - Cultura regional. }\end{array}$ \\
\hline $\begin{array}{l}\text { Desafios de su- } \\
\text { porte }\end{array}$ & $\begin{array}{l}\text { Incentivo da instituição } \\
\text { frente às mudanças }\end{array}$ & $\begin{array}{l}\text { - Exigência top-down; } \\
\text { - Compromisso da instituição; } \\
\text { - Indicadores de desempenho; } \\
\text { - Papel da coordenação do curso. }\end{array}$ \\
\hline $\begin{array}{l}\text { Desafios compor- } \\
\text { tamentais }\end{array}$ & $\begin{array}{l}\text { Motivadores e obstáculos } \\
\text { de ordem pessoal para a } \\
\text { realização das mudanças }\end{array}$ & $\begin{array}{l}\text { - Comprometimento; } \\
\text { - Interesse pelo tema; } \\
\text { - Resistência à mudança. }\end{array}$ \\
\hline $\begin{array}{l}\text { Natureza da dis- } \\
\text { ciplina }\end{array}$ & $\begin{array}{l}\text { Caso exista, como a(s) dis- } \\
\text { ciplina(s) é(são) ofertada } \\
\text { aos alunos }\end{array}$ & $\begin{array}{l}\text { - Disciplina de caráter obrigatório; } \\
\text { - Disciplina de caráter eletivo. }\end{array}$ \\
\hline $\begin{array}{l}\text { Presença no cur- } \\
\text { rículo }\end{array}$ & $\begin{array}{l}\text { Como a temática Susten- } \\
\text { tabilidade está presente no } \\
\text { currículo }\end{array}$ & $\begin{array}{l}\text { - Disciplinar (disciplina isolada); } \\
\text { - Cross-disciplinar (transversal); } \\
\text { - Interdisciplinar; } \\
\text { - Multidisciplinar; } \\
\text { - Transdisciplinar. }\end{array}$ \\
\hline Extensão & $\begin{array}{l}\text { Projetos de extensão rela- } \\
\text { cionados com a temática } \\
\text { Sustentabilidade }\end{array}$ & $\begin{array}{l}\text { - Parceria com o setor privado; } \\
\text { - Parceria com o setor público; } \\
\text { - Parceria com a sociedade civil. }\end{array}$ \\
\hline Pesquisa & $\begin{array}{l}\text { Presença de linhas de } \\
\text { pesquisa sobre a temática } \\
\text { Sustentabilidade }\end{array}$ & $\begin{array}{l}\text { - Linha de pesquisa direta; } \\
\text { - Linha de pesquisa indireta; } \\
\text { - Grupo de pesquisa. }\end{array}$ \\
\hline
\end{tabular}




\section{A SUSTENTABILIDADE SOB AS LENTES DA INSTITUIÇÃO DE ENSINO}

A Universidade foco deste artigo está localizada no Estado do Rio Grande do Sul, extremo sul do Brasil. A região onde está inserida foi, por muito tempo, o principal polo coureiro-calçadista do país. No entanto, a indústria calçadista nacional tem sido cada vez mais pressionada por produtos asiáticos, de qualidade similar, mas com preço menor, e pelos produtos italianos de preço mais elevado, mas com melhor imagem no mercado internacional. Nesse sentido, na busca por mão de obra de menor custo e pela obtenção de benefícios fiscais, algumas empresas passaram a se deslocar para outras regiões, principalmente para o Nordeste, em cidades frequentemente afastadas das capitais e sem tradição na produção de calçados. Tal fenômeno gerou uma diversificação nas atividades empresariais da região.

A instituição de ensino superior (IES) analisada caracteriza-se por sua identidade comunitária, comprometida com o desenvolvimento regional e com a inovação tecnológica. O plano de desenvolvimento institucional (PDI) apresenta como princípios de atuação a responsabilidade social e a sustentabilidade socioambiental e prevê esses temas em suas políticas, a partir de várias diretrizes que também norteiam a avaliação dos projetos político-pedagógicos dos cursos. De acordo com a pró-reitora de ensino, ênfase é dada ao perfil do egresso da instituição que prevê, além da formação técnica, uma formação humana, de entendimento do sujeito no mundo: "[...] eu, enquanto sujeito neste mundo, tenho que ter capacidade de identificar, de diagnosticar, de promover intervenções e de avaliar as minhas intervenções nesse mundo. E a sustentabilidade está permeada em várias destas competências pessoais" (PE). Esse perfil serve como base para o perfil do egresso de cada curso, refletindo-se nas competências desejadas dos profissionais que são formados na instituição.

Pode-se dizer que a instituição busca ser exemplo para a comunidade acadêmica, pois suas diretrizes não estão apenas nos documentos ou no discurso. Como principal referência institucional de prática ligada a questões 
socioambientais, tem-se o Grupo Interno de Gerenciamento Ambiental (GIGA), responsável pelas atividades relacionadas à estação de tratamento de esgoto (ETE) e ao descarte de resíduos comuns, eletrônicos e de laboratórios. De acordo com a engenheira entrevistada, inicialmente, o grupo era formado por professores que se reuniam para dar palestras em escolas da região, o foco era essencialmente a educação ambiental e permaneceu nesse formato de 1997 a 2002. Com a ampliação estrutural da universidade, percebeu-se a necessidade de criar um setor que pudesse gerir os resíduos. Atualmente, conta com uma central onde é realizada toda a triagem do material que, posteriormente, é destinado a empresas de reciclagem. O setor também é responsável pelo recolhimento e pela destinação adequada dos resíduos de laboratórios e realiza a coleta de eletrônicos uma vez por mês, contando com a participação de toda a comunidade.

O GIGA permite uma aproximação dos alunos, a partir de visitas programadas em conjunto com os professores que manifestam interesse. Esse olhar mais próximo para o funcionamento de uma estação de tratamento de esgotos e para a central de resíduos permite a estudantes dos mais variados cursos vivenciarem uma realidade que, na maioria das vezes, desconhecem. Apesar de perceber um aumento do interesse da comunidade acadêmica por questões ambientais, a entrevistada (EGA) reconhece que poderia haver uma participação ainda mais significativa, mas muitos professores desconhecem essa possibilidade. Sugere-se que haja uma comunicação das coordenações de curso ao seu corpo docente nesse sentido, considerando, principalmente o relato da engenheira:

[...] quanto mais alunos forem lá, melhor. Uma coisa que eles não sabem e, quando chegam lá [na central de resíduos] ficam meio assustados, é o copinho de café. Eles não sabem que aquele copo não dá para reciclar. Eles chegam e veem aquele monte de copinhos de café que vão pro aterro. Dizem: 'bah, vou começar a trazer minha canequinha' $[\ldots .$. 'vou trazer minha garrafa pra não precisar usar copo plástico’ (EGA).

É importante mencionar que o GIGA também oferece orientação aos profissionais da higienização que trabalham na universidade e às em- 
presas que estão instaladas no campus, como instituição bancária, lojas e restaurantes. O relato é de um feedback bastante positivo por parte dessas empresas, que mudam suas práticas visando reduzir a geração de resíduos bem com separá-los corretamente.

Na universidade, também merecem destaque os projetos com perspectiva social, como o convênio de combate e prevenção à dengue; o "Força na Peruca", evento semestral em parceria com a ONG Cabelaço, que tem a finalidade de coletar mechas de cabelos para a confecção de perucas para crianças e adolescentes com câncer; e o teste de tipagem sanguínea oferecida pelo curso de Biomedicina, apenas para citar alguns exemplos.

Por ser filantrópica, o incentivo e a destinação de recursos a projetos de extensão é outra importante característica da instituição. Como exemplo, tem-se o projeto de extensão Gestão em Empreendimentos Solidários, vinculado ao Instituto do qual o Curso de Administração faz parte. O referido projeto presta assessoria a Cooperativas de Reciclagem da região do Vale do Sinos. As vagas para bolsistas, remunerados ou voluntários, oportunizam que os estudantes relacionem, sob uma perspectiva prática, sustentabilidade e gestão, além de possibilitarem uma aproximação com uma realidade social diferente da sua, permitindo a reflexão e o exercício da empatia. Atualmente, a instituição conta com 37 projetos de extensão nas mais diversas áreas.

Outro aspecto considerado quando se trata da relação da IES com a sustentabilidade é sua Comissão Própria de Avaliação (CPA). Segundo o coordenador administrativo entrevistado, o programa de avaliação institucional da universidade trata a sustentabilidade em diferentes perspectivas, associadas aos pilares do desenvolvimento sustentável (social, ambiental e econômico), quais sejam: responsabilidade social, preservação do meio ambiente e sustentabilidade financeira. No entanto, envolvem prioritariamente elementos de adequação considerados pelo Ministério da Educação nas avaliações de cursos ou mesmo na criação de novos cursos. Desse modo, nos instrumentos de avaliação utilizados tanto para alunos como para docentes e demais funcionários, não existe nenhum questionamento específico sobre questões sociais ou ambientais. Existem, sim, questões ligadas à 
infraestrutura, que se preocupam mais com a questão estrutural e arquitetônica dos diferentes espaços da universidade.

Apesar de o entrevistado considerar importante, percebeu-se que não há um movimento visando inserir questões que façam referência direta à sustentabilidade, tendo em vista que a tentativa é reduzir o tamanho do atual instrumento de avaliação institucional. Mas, como os alunos e os professores percebem as práticas sociais e ambientais da instituição? Também não há um monitoramento efetivo das práticas de responsabilidade social. Nas palavras do entrevistado, "talvez a sustentabilidade esteja posta num segundo plano e a gente nem tem dado a devida atenção que ela merece [na avaliação]" (CCPA). Ficou evidente a preocupação com a infraestrutura, com os processos de ensino e aprendizagem, incluindo avaliação do professor, do monitor, dos tutores das disciplinas à distância, por exemplo. Em contrapartida, ficou claro que existe espaço e intenção para a mudança no instrumento que avalia os 32 empreendimentos que prestam serviços no câmpus, o que pode ser considerado como um ponto de partida para uma mudança mais global em termos de avaliação institucional. Nesse sentido, ele reforça: "fazer um instrumento é a parte mais simples do processo, o mais complexo é entender para que ele serve" (CCPA) e quais os seus desdobramentos.

Já em relação à avaliação externa (SINAES), na percepção da pró-reitora de ensino, o que mais chamou atenção foi a ênfase dada às questões de inovação em sala de aula dos processos de ensino e aprendizagem. Mas, especificamente, em relação à sustentabilidade:

em nenhum dos indicadores considerados na avaliação in loco, por exemplo, que é o instrumento maior de avaliação de curso, não tem nenhum que trate especificamente da questão da sustentabilidade nos cursos. Mas permeia. [...] principalmente nos itens que tratam das questões pedagógicas, da formação do aluno (PE).

No entanto, vale lembrar que, em se tratando da perspectiva curricular, de acordo com as diretrizes constantes no instrumento de avaliação (INEP, 2019b), deve ser considerada a presença da educação ambiental nos 
currículos. Mas esse fato não garante a transversalidade do tema. Em outras palavras, uma avaliação dicotômica, o "sim ou não" marcado no instrumento de avaliação não garante que tenha sido alcançada a aprendizagem desejada. O curso de Administração e o foco no currículo são tratados na seção que segue. 


\section{O CURSO DE ADMINISTRAÇÃO E A SUSTENTABILIDADE NO CURRÍCULO}

A Universidade oferece, atualmente, 51 cursos de graduação. De entre os objetivos constantes no projeto político pedagógico do Curso de Administração, pode-se destacar a importância dada à formação considerando a cidadania, a visão crítica, o senso ético e a responsabilidade social. As mudanças na economia local também geraram mudanças no curso que, até a década de 1990, possuía basicamente alunos do setor coureiro-calçadista atuantes nas empresas da região. Essa realidade também se aplicava ao corpo docente, formado basicamente por profissionais desse mesmo segmento. Atualmente, tem-se um grupo de alunos com demandas diversas.

O curso oferece aos acadêmicos um rol de disciplinas específicas responsável pela formação geral em gestão e também oferece um grupo de disciplinas optativas organizadas de forma a proporcionar conhecimentos específicos nas áreas de marketing, produção/operação, humanística, recursos humanos e finanças. No primeiro semestre do ano de 2018, o curso possuía 910 alunos matriculados e um currículo que oferece 75 disciplinas.

Conforme detalhado na seção de metodologia, para o processo de busca na ementa, nos objetivos e nos programas de aprendizagem de cada plano de ensino, foram utilizadas as seguintes palavras-chave: sustentabilidade, desenvolvimento sustentável e socioambiental - social/ ambiental. A partir de uma leitura cuidadosa de todos os planos de ensino, também se observou a presença de termos correlatos, como, por exemplo: natureza, ética, verde, resíduos, reciclagem, logística reversa, consumo consciente, etc.

A relação, direta ou indireta, com a temática sustentabilidade foi identificada em 9 disciplinas, em 4 obrigatórias e em 5 optativas. O Quadro 3 apresenta a configuração encontrada. Na disciplina de Marketing Estratégico, encontrou-se o termo "sustentabilidade", mas explicitamente relacionado à manutenção da empresa no mercado, portanto, a disciplina não consta no quadro. Além disso, das três disciplinas optativas que ainda não foram ofertadas, conforme detalhado nos procedimentos metodológicos, 


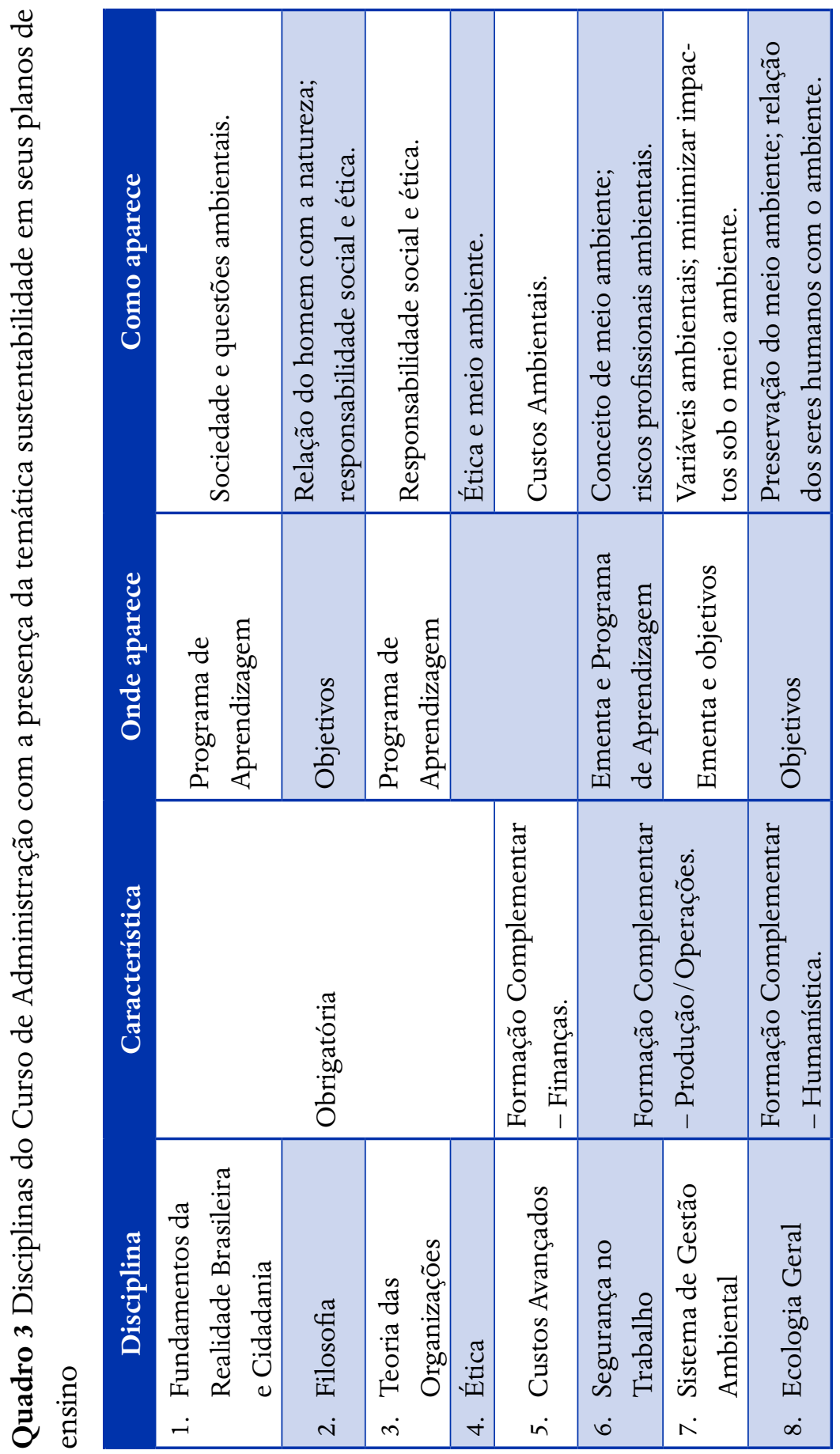


consta a disciplina de Responsabilidade Social e Ética, cuja relação seria direta e explícita com a temática em análise.

Além das disciplinas já mencionadas, tem-se também a de Introdução à Administração, oferecida no $1^{\circ}$ semestre, em que há a possibilidade de uma relação indireta com a sustentabilidade, levando em consideração que o plano de aprendizagem traz o papel do administrador frente aos novos paradigmas. Mas isso depende exclusivamente do interesse do docente. Na percepção do coordenador do curso de Administração, a sustentabilidade de fato é um tema multidisciplinar e que cada vez mais está presente no dia a dia das empresas e da sociedade em geral. Reconhece o fato de que o tema não é tratado em todas as áreas, levando em conta que não há uma orientação formal da instituição ou do curso para que isso aconteça.

Autores como Lessa, Spier e Nascimento (2018), Setó-Pamies e Papaoikonomou (2016), Figueiró e Raufflet (2015), Kurucz, Colbert e Marcus (2013) e Thomas, Hergarty e Holdsworth (2012) apresentam em seus trabalhos barreiras de ordem organizacional, pedagógica, conceitual e, inclusive, comportamental para uma efetiva integração da sustentabilidade no ensino em gestão. Mas, para o coordenador entrevistado, dificilmente haverá algum tipo de resistência a propostas dessa natureza, levando em consideração o perfil da instituição e do atual grupo de docentes. Em sua percepção, seria como ser contra, por exemplo, o avanço digital, ou seja, contra algo necessário, enriquecedor e inevitável.

Na percepção da pró-reitora, um elemento que pode dificultar o processo de mudança são as concepções de cada indivíduo, questões de ordem cultural. $\mathrm{O}$ fato de que as pessoas tendem a não perceber a solução, mas os problemas, algo que está intrínseco no entendimento, nos conceitos e preconceitos de cada um. Para exemplificar, a entrevistada traz que

não adianta a pessoa fazer um discurso em sala de aula para o aluno dizendo - nós precisamos pensar na questão ambiental, que obviamente envolve a questão econômica, que obviamente vem da questão social - se ele mesmo, na sua prática, acha que é horrível ganhar uma canequinha, porque não vai mais ter copinho de plástico na sala de professores (PE). 
Ligado à prática docente, percebeu-se que não existe um acompanhamento acerca das didáticas e práticas em sala de aula, incluindo aquelas que extrapolam o plano de ensino e são oferecidas voluntariamente, de acordo com o interesse e a disponibilidade do professor. Assim, por um lado, mesmo nas disciplinas em que a sustentabilidade não consta de maneira explícita, não se pode afirmar que o tema não seja trazido em algum momento. Por outro lado, mesmo explícito no plano de ensino não quer dizer que exista criticidade ou reflexão acerca do conteúdo. É possível inferir que envolve uma relação de dependência do docente. Um exemplo dessa situação foi destacado justamente pelo coordenador entrevistado. A disciplina de Marketing, na qual atua como docente, não traz uma relação explícita com a temática sustentabilidade no plano de ensino, conforme já mencionado anteriormente. Mas aborda uma nova alternativa estratégica para desenvolvimento das organizações, o Marketing 3.0, um modelo que, segundo ele, permite discussões ligadas a diferentes perspectivas da sustentabilidade.

Outro exemplo é a disciplina de Empreendedorismo e Plano de Negócios que também não apresenta explicitamente o tema no plano de ensino. No entanto, em uma das aulas, um dos docentes da disciplina convida uma professora que trabalha com empreendedorismo social para discutir o assunto e estimular os estudantes para que considerem essa perspectiva na criação dos negócios. É uma ação isolada e que denota a dependência dos docentes que atuam diretamente com a temática e que, voluntariamente, se dispõem a levar o tema para as aulas.

O coordenador menciona não perceber uma grande procura pelo tema quando se trata de pesquisa voltada aos trabalhos de conclusão. Isso pode estar relacionado ao fato de não existir uma disciplina obrigatória, bem como ao de que a sustentabilidade seja um tema de pesquisa diretamente relacionado a somente três professores do curso. Esses docentes também coordenam projetos de iniciação científica na área, o que possibilita uma aproximação dos estudantes com a temática, seja como bolsistas ou como voluntários.

É pertinente trazer que, durante a coleta de dados, estava sendo planejada a reforma curricular do curso. Essa reforma prevê a oferta da 
disciplina de Gestão Socioambiental e também a de Empreendedorismo Social, que será trabalhada sob a perspectiva da Inovação Social. Essa inclusão, apesar de não remeter à transversalidade, garante que o tema seja apresentado aos estudantes em diferentes perspectivas. Além disso, outro elemento que tem recebido cada vez mais atenção por parte da instituição é a atividade docente, fundamentada na prática e na promoção de vivências aos estudantes. Nesse cenário, o "coordenador não é mais só coordenador, $[\ldots]$ para que o professor seja um bom maestro, o coordenador tem que ser um bom maestro [...]” (PE), no sentido de realizar uma conexão com os docentes e destes com os objetivos institucionais.

Alinhado a isso, nesse processo de mudança curricular, que com o tempo abrangerá todos os cursos, a pró-reitora de ensino reforça a presença de atividades de extensão em parte das disciplinas, a chamada curricularização da extensão. Considerando que "a realidade traz sempre a necessidade de se pensar a sustentabilidade" (PE), essa prática vai contribuir para a presença da temática no ensino, pois vai envolver diagnóstico, intervenção e avaliação das atividades realizadas pelos alunos. Desse modo, de acordo com a pró-reitora entrevistada, o professor terá maiores condições de trabalhar em uma perspectiva prática e experiencialos contextos que são transversais, como inovação, empreendedorismo e sustentabilidade. 


\section{A VISÃO DOS FUTUROS GESTORES}

A etapa quantitativa da pesquisa, realizada com os estudantes matriculados em semestres finais do curso indica certa miopia no entendimento sobre o tema. Os respondentes, em sua maioria, associam a sustentabilidade ou desenvolvimento sustentável à preservação do meio ambiente ou à redução de resíduos (39\%); outros $21 \%$ associam à preocupação com as próximas gerações. Questões de ordem social praticamente foram inexistentes nas respostas. No grupo focal, ocorreu o mesmo. Para se referir à sustentabilidade ou ao desenvolvimento sustentável todos utilizaram termos como: 'não prejudicar a natureza'; 'reaproveitamento de materiais'; 'usar materiais reciclados'; 'sustentabilidade ambiental'; 'pensar no amanhã, principalmente em relação ao meio ambiente'; 'dar a destinação correta para os resíduos da indústria', apenas para citar alguns exemplos. Quando discutida sob a perspectiva social, alguns estudantes manifestaram que a sustentabilidade normalmente é responsabilidade do setor de gestão de pessoas. Envolve, portanto, uma visão bastante reducionista sobre a temática. Tal constatação vai ao encontro do trazido por Demajorovic e Silva (2012); Richter e Schumacher (2011); e Benn e Dunphy (2009).

No que se refere à formação dos gestores, $98 \%$ consideraram de extrema importância ou importante a presença da temática sustentabilidade durante sua formação. No entanto, apenas $36 \%$ entendem que ela está relacionada a todas as áreas da empresa. No grupo focal, chama atenção a opinião cética da maior parte dos participantes sobre o papel desempenhado pelos gestores. As respostas giraram em torno do cumprimento da legislação, a fim de evitar multas. Também percebem a prática da sustentabilidade nas empresas meramente como estratégia para gerar uma imagem positiva, para captar ou manter clientes; por fim, foi mencionada a redução de custos, a partir da economia de energia, por exemplo.

Associado a isso, $58 \%$ dos estudantes não se sentem preparados para atuar na área ou propor projetos relacionados ao tema e apenas $16 \%$ mencionam ter percebido a presença do tema em disciplinas de diferentes áreas ao longo do curso, entre as quais destacam: Empreendedorismo e Plano de 
Negócios, Gestão da Inovação, Gestão de Operações, Marketing e Teorias Organizacionais I e II. Ainda assim, quando questionados sobre estudos acerca do tema ao longo do curso, $72 \%$ afirmaram ter tido contato de maneira informal, por meio de algumas leituras, de vídeos apresentados em aula e de exemplos dados por alguns professores. Trata-se de um percentual significativo, mas o fato de não se sentirem preparados para atuar na área denota uma possível superficialidade na forma como o assunto está sendo trazido, conforme destacado por Brunstein, Sambiase e Brunnquell (2018); Figueiró (2015); Sharma e Hart (2014); e Carvalho, Brunstein e Godoy (2014).

O exposto foi reforçado pelo grupo focal realizado. Ao trazerem para o debate se durante o curso haviam participado de estudos e discussões sobre o tema, a maioria dos estudantes indicou que, se isso aconteceu, foi pontualmente em algumas aulas ou por meio de exemplos. A lembrança mais concreta está relacionada principalmente aos tópicos estudados na disciplina de Fundamentos da Realidade Brasileira. O relato a seguir traduz o exposto:

eu tive aula com vários professores, [...] se for avaliar, vai do perfil do professor também, fazer este comentário ou não. Uns não comentaram nada, outros comentaram. De sete, oito aulas que eu tenho, acho que [somando] não deu uma aula [completa] sobre o assunto. Mas, volto a dizer, vai do interesse de quem está passando e do próprio aluno, buscar e fazer um trabalho. É uma vontade pessoal mudar. Eu acredito que a maioria tem, talvez não saiba como fazer. Eu acho que isto pesa bastante (GF).

Diante disso, pode-se dizer que a transversalidade, ou seja, a presença da temática nas diferentes áreas e disciplinas depende exclusivamente do interesse e da iniciativa dos professores, reforçando um dos principais desafios da relação entre educação e sustentabilidade, destacado por Richter e Schumacher (2011) e Davis et al. (2003). Nesse sentido, foi mencionado por dois participantes que, como são formados tantos administradores pela instituição, é importante que haja pelo menos uma disciplina obrigatória que trate especificamente do assunto. Essa reivindicação acabou sendo atendi- 
da na reforma curricular realizada, já que está sendo incluída a disciplina de Gestão Socioambiental e também a de Empreendedorismo Social, conforme já mencionado. Ainda assim, os alunos sugerem que outras disciplinas também podem tratar do tema, como, por exemplo, um enfoque ligado à inclusão social em disciplinas de gestão de pessoas, sugestão bastante reforçada durante as falas.

A importância de um maior aprofundamento sobre o tema dá-se na medida em que os participantes do grupo focal também não se sentem preparados para propor projetos ou iniciativas sobre a temática, apenas algo mais básico, como a separação de lixo mencionada por três estudantes. Mesmo considerando que a mudança de cultura nas organizações deve partir dos gestores, foram raros os momentos de segurança dos participantes ao falarem sobre o assunto. As seguintes expressões corroboram o exposto: 'a gente não domina o assunto'; 'a gente não tem um conhecimento tão a fundo'. De forma complementar: "eu sou formado em 'técnico em meio ambiente', por isso eu acho que sim, mas não pelo curso de Administração [...]"; "saindo agora da universidade como administradora eu tenho uma visão muito de inovação. Tipo 'ah, vamos automatizar isto', ou 'isto aqui daria para automatizar', mas questões sustentáveis, eu não me sinto hoje preparada".

Entende-se também que as atividades extracurriculares são fundamentais para garantir o contato dos discentes com assuntos de natureza social e/ou ambiental. Quando questionados sobre a oportunidade de participarem de projetos ligados à sustentabilidade, propostos pelo curso de Administração ou pela universidade como um todo, somente $40 \%$ indicaram conhecer projetos desse tipo dentro da universidade. Desses, $10 \%$ citaram o GIGA (Grupo Interno de Gestão Ambiental) como principal responsável pela sua elaboração e divulgação. Esses reduzidos percentuais indicam a necessidade de uma maior divulgação dos projetos e das práticas de natureza social e/ ou ambiental realizados no ambiente universitário, bem como da oportunidade que os alunos possuem de se envolverem nesse cenário.

Por fim, percebeu-se que o MEC, no momento da avaliação do curso, não é enfático ao considerar a transversalidade do tema, conforme indica 
sua própria diretriz. De acordo com Petarnella, Silveira e Machado (2017), atualmente, políticas que integrem a educação e a sustentabilidade são quase nulas e há pouca legislação rigorosa e, portanto, efetiva sobre o tema. Assim, no Brasil, tendo em vista que a transversalidade não é obrigatória, o fato de existir uma disciplina, mesmo que optativa, já cumpre o requisito legal. O que, de fato, não garante uma visão sistêmica e crítica a respeito da relação entre as questões ligadas à sustentabilidade e às diferentes áreas da gestão.

A partir da discussão apresentada, o Quadro 4 busca associar, de forma resumida, os principais achados da pesquisa às categorias e aos elementos de análise considerados. 


\section{Quadro 4 A temática Sustentabilidade no Curso de Administração}

\begin{tabular}{|c|c|c|}
\hline Categorias & Elementos de análise & $\begin{array}{c}\text { Universidade } \\
\text { Curso de Administração }\end{array}$ \\
\hline Governo & $\begin{array}{l}\text { - Influência da exigência } \\
\text { legal frente às } \\
\text { mudanças. }\end{array}$ & $\begin{array}{l}\text { A avaliação institucional gera uma } \\
\text { preocupação voltada principalmente } \\
\text { ao perfil do egresso, à prática docente } \\
\text { e a questões estruturais. }\end{array}$ \\
\hline $\begin{array}{l}\text { Natureza da } \\
\text { IES }\end{array}$ & $\begin{array}{l}\text { - Natureza Pública; } \\
\text { - Natureza Privada. }\end{array}$ & $\begin{array}{l}\text { Instituição privada, comunitária, } \\
\text { filantrópica. }\end{array}$ \\
\hline $\begin{array}{l}\text { Localização } \\
\text { geográfica }\end{array}$ & $\begin{array}{l}\text { - Desenvolvimento } \\
\text { regional; } \\
\text { - Cultura regional. }\end{array}$ & $\begin{array}{l}\text { Economia diversificada, a partir da } \\
\text { crise coureiro-calçadista. Com isso, } \\
\text { cultura mais propícia à inovação. }\end{array}$ \\
\hline $\begin{array}{l}\text { Desafios de } \\
\text { suporte }\end{array}$ & $\begin{array}{l}\text { - Exigência top-down; } \\
\text { - Compromisso da } \\
\text { instituição; } \\
\text { - Papel da coordenação } \\
\text { do curso. }\end{array}$ & $\begin{array}{l}\text { Não há exigência top-down, apesar de } \\
\text { constar direta e indiretamente no PDI; } \\
\text { Práticas de Responsabilidade Social; } \\
\text { Formação oferecida pelo GIGA às } \\
\text { empresas terceiras e funcionários da } \\
\text { higienização e manutenção; } \\
\text { Amplo incentivo à projetos de } \\
\text { extensão; } \\
\text { Coordenação do curso entende que } \\
\text { não existe a presença transversal do } \\
\text { tema na formação. }\end{array}$ \\
\hline $\begin{array}{l}\text { Desafios } \\
\text { comporta- } \\
\text { mentais }\end{array}$ & $\begin{array}{l}\text { - Comprometimento; } \\
\text { - Interesse pelo tema; } \\
\text { - Resistência à mudança. }\end{array}$ & $\begin{array}{l}\text { Apesar do entendimento sobre a } \\
\text { importância do tema e das práticas } \\
\text { organizacionais já existentes, necessita } \\
\text { de um comprometimento mais efetivo } \\
\text { frente à formação dos estudantes; } \\
\text { Questões de ordem cultural do indiví- } \\
\text { duo podem gerar resistência; } \\
\text { Na perspectiva da coordenação, não } \\
\text { existiria resistência em caso de reo- } \\
\text { rientação curricular. }\end{array}$ \\
\hline
\end{tabular}




\begin{tabular}{|c|c|c|}
\hline $\begin{array}{l}\text { Natureza da } \\
\text { disciplina }\end{array}$ & $\begin{array}{l}\text { - Disciplina de caráter } \\
\text { obrigatório; } \\
\text { - Disciplina de caráter } \\
\text { eletivo. }\end{array}$ & $\begin{array}{l}\text { Reforma curricular prevendo duas dis- } \\
\text { ciplinas de caráter obrigatório (Gestão } \\
\text { Socioambiental e Empreendedorismo } \\
\text { Social); } \\
\text { Disciplina de caráter eletivo ofertada } \\
\text { em outros cursos: Sistema de Gestão } \\
\text { Ambiental; } \\
\text { Disciplina de caráter eletivo ofertada } \\
\text { na Administração: Responsabilidade } \\
\text { Social e Ética. }\end{array}$ \\
\hline $\begin{array}{l}\text { Presença no } \\
\text { currículo }\end{array}$ & $\begin{array}{l}\text { - Disciplinar; } \\
\text { - Transversal; } \\
\text { - Interdisciplinar; } \\
\text { - Multidisciplinar; } \\
\text { - Transdisciplinar. }\end{array}$ & $\begin{array}{l}\text { Presença da temática em algumas } \\
\text { disciplinas obrigatórias e eletivas, } \\
\text { portanto, não se caracteriza como } \\
\text { transversal; } \\
\text { Oferta da disciplina (eletiva) de Siste- } \\
\text { ma de Gestão Ambiental o que não } \\
\text { garante a presença integral do tema na } \\
\text { formação. }\end{array}$ \\
\hline Extensão & $\begin{array}{l}\text { - Parceria com o setor } \\
\text { privado; } \\
\text { - Parceria com o setor } \\
\text { público; } \\
\text { - Parceria com a socie- } \\
\text { dade civil. }\end{array}$ & $\begin{array}{l}\text { O projeto de extensão ligado ao Curso } \\
\text { de Administração possui parceria com } \\
\text { a Prefeitura Municipal e atua junto à } \\
\text { sociedade com ênfase na geração de } \\
\text { renda para catadores de cooperativas } \\
\text { de reciclagem. }\end{array}$ \\
\hline Pesquisa & $\begin{array}{l}\text { - Linha de pesquisa } \\
\text { direta; } \\
\text { - Linha de pesquisa } \\
\text { indireta; } \\
\text { - Grupo de pesquisa. }\end{array}$ & $\begin{array}{l}\text { Pesquisas diretas de três docentes que } \\
\text { atuam na área, incluindo a coordena- } \\
\text { ção de projetos de Iniciação Científica } \\
\text { e grupos de pesquisa. }\end{array}$ \\
\hline
\end{tabular}

A partir do exposto, a seguir tem-se as considerações finais acerca dos resultados discutidos nesta seção. 


\section{CONSIDERAÇÕES FINAIS}

A presente pesquisa teve como objetivo analisar em que medida elementos contextuais, organizacionais e curriculares colaboram para a formação superior em Administração sob a perspectiva da sustentabilidade. Para a coleta de dados, usaram-se os planos de ensino das 75 disciplinas ofertadas no curso. Também foram realizadas entrevistas com quatro atores institucionais chave para o entendimento contextual e organizacional. Além disso, foram utilizados o PDI da instituição e o PPC do curso e aplicados questionários aos alunos matriculados nos últimos dois semestres do curso. A fim de aprofundar o entendimento dos dados obtidos nas etapas anteriores, foi realizado um grupo focal também com estudantes em final de curso.

Primeiramente, na perspectiva contextual, pode-se dizer que a avaliação institucional externa (SINAES) está mais focada na infraestrutura, na prática docente e no perfil do egresso. A sustentabilidade permeia principalmente o perfil do egresso e é considerada pelo instrumento de avaliação apenas de forma dicotômica (sim ou não) quanto à presença em alguma disciplina, mesmo que eletiva.

$\mathrm{Na}$ dimensão organizacional, fica evidente que existem práticas, principalmente sociais, mas parecem mais decorrentes da característica comunitária e filantrópica da instituição do que de um viés estratégico. Pode-se dizer que a presença do GIGA institucionaliza a importância da questão ambiental na comunidade acadêmica, sendo que uma maior comunicação sobre suas atividades junto aos docentes pode estimular a aproximação com os alunos a partir de visitas técnicas, por exemplo. A CPA pode exercer um papel mais ativo no que tange a uma maior compreensão acerca do impacto das ações e atividades de cunho socioambiental oferecidas pela IES. Incluir tais elementos na avaliação pode oferecer um direcionamento estratégico para a instituição.

Em relação ao curso de Administração, os planos de ensino analisados, com base nas palavras-chave mencionadas nos procedimentos metodológicos, demonstram que a temática sustentabilidade está presente em nove disciplinas ofertadas, na seguinte composição: das 38 disciplinas 
obrigatórias oferecidas pelo curso, quatro apresentam relação direta com a temática em análise; e das 34 disciplinas optativas, quatro também fazem essa relação, lembrando que a quinta disciplina (Marketing Estratégico) traz uma das palavras-chave, mas com conotação diferente da considerada nesta pesquisa. Isso demonstra que o tema está presente apenas de maneira pontual em algumas disciplinas do primeiro e do segundo semestres e em outras de categoria optativas.

Os resultados permitem inferir que, apesar de não haver uma orientação formal do Curso, a coordenação reconhece a importância do tema tanto para os estudantes como para as organizações e para a sociedade em geral. Alinhado a isso, durante o processo de coleta de dados, estava sendo elaborada a reforma curricular do curso que prevê a oferta de duas disciplinas obrigatórias diretamente ligadas ao tema: Gestão Socioambiental e Empreendedorismo Social. Isso é considerado um avanço bastante significativo, porque pode gerar desdobramentos que remetem inclusive a um maior interesse por pesquisas sobre o tema nos trabalhos de conclusão, bem como a uma mudança de percepção por parte dos estudantes de que a sustentabilidade está ligada apenas ao meio ambiente.

Na percepção dos respondentes e dos participantes do grupo focal, é possível afirmar que, até aquele momento, a temática era pouco explorada em sala de aula e, quando trazida, era de maneira informal, o que acaba deixando-os inseguros para trabalharem com tais questões no seu ambiente profissional. O intuito é que as disciplinas acima mencionadas alterem esse cenário. Muitos estudantes não identificam nas organizações em que atuam projetos ligados ao tema, o que não permite um contato direto com o assunto (no âmbito da gestão) fora da sala de aula. Essa afirmação abre precedente para que se reflita acerca da importância que esse profissional seja proponente ou mesmo um disseminador de práticas e estratégias que levem em consideração questões sociais e ambientais. Oportuniza também um movimento que incentive uma maior participação dos estudantes em projetos de extensão.

O curso, mesmo que aborde a temática analisada, ainda está carente de um maior aprofundamento e também de explorar as diversas possibili- 
dades de interdisciplinaridade que o assunto proporciona. Além disso, identifica-se a necessidade de uma maior divulgação de práticas e projetos para que os acadêmicos tenham a oportunidade de uma aprendizagem mais ativa, inclusive atuando em projetos de extensão junto à comunidade.

A sociedade em geral necessita mudanças na forma de conviver - entre si e com o ambiente - e isso só será possível por meio da educação. O intuito, diante do exposto, é permitir a formação profissional de administradores mais conscientes que poderão estimular e propor mudanças efetivas junto ao ecossistema do qual fazem parte, algo cada vez mais necessário em um mundo carente de profissionais que considerem o ser humano e sua relação com o ambiente que o cerca. A temática sustentabilidade envolve, entre tantos outros assuntos, responsabilidade social, geração de valor compartilhado, gestão da diversidade e inclusão, ética, produção mais limpa, finanças sociais, marketing social, empreendedorismo social e negócios de impacto, logística reversa, apenas para citar alguns. O que se espera é a formação integral de um profissional crítico e reflexivo quanto a essas questões e todas as oportunidades que oferecem.

Como sugestão de pesquisas futuras, tem-se a coleta de dados juntos aos professores do Curso de Administração, considerando a dimensão pedagógica; e a realização de entrevista com os membros do NDE (Núcleo Docente Estruturante). A partir da mudança curricular, indica-se realizar um estudo comparativo entre os egressos vinculados aos diferentes currículos. Estudos comparativos com outras instituições também são indicados, bem como sua replicação em cursos de graduação de outras áreas e na pós-graduação. Por fim, também se sugere a discussão sob a luz da teoria institucional, principalmente considerando a influência das dimensões contextual e organizacional diante da matriz curricular e das práticas pedagógicas dos cursos. 


\section{REFERÊNCIAS}

ALVES, R. R. Administração Verde: o caminho sem volta da Sustentabilidade ambiental nas organizações. 1. ed. Rio de Janeiro: Editora Elsevier, 2016. 328 p.

ANDERBERG, E.; NORDÉN, B.; HANSSON, B. Global learning for sustainable development in higher education: recent trends and a critique. International Journal of Sustainability in Higher Education, v.10, n.4, p.368-378, 2009.

BARDIN, L. Análise de Conteúdo. São Paulo: Edições 70, 2011. 279p.

BELL, D. V. J. Twenty-first Century Education: Transformative Education for Sustainability and Responsible Citizenship. Journal of Teacher Education for Sustainability, v.18, n.1, p.48-56, 2016.

BENN, S.; DUNPHY, D. Action Research as an Approach to Integrating Sustainability into MBA Programs: an exploratory study. Journal of Management Education, v.33, n.3, p. 276-295, 2009.

BROSTRÖM, A.; FELDMANN, A.; KAULIO, M. Structured relations between higher education institutions and external organisations: opportunity or bureaucratisation? Higher Education, p.1-17, 2019.

BRUNSTEIN, J.; GODOY, A. S.; SILVA, H. C. Educação para Sustentabilidade nas Escolas de Administração. 1. ed. São Carlos: Rima Editora, 2014. 374 p.

BRUNSTEIN, J.; SAMBIASE, M. F.; BRUNNQUELL, C. An Assessment of Critical Reflection in Management Education for Sustainability: A Proposal on Content and Form of Shared Value Rationality. Sustainability, v.10, p.1-25, 2018.

CARVALHO, S. L. G.; BRUNSTEIN, J.; GODOY, A. S. Um panorama das discussões sobre educação para a sustentabilidade no ensino superior e nos cursos de administração. In: BRUNSTEIN, J.; GODOY, A. S.; SILVA, H. C. (Orgs.) Educação para Sustentabilidade nas Escolas de Administração. São Carlos: RiMa Editora, 2014, cap.5.

CNCS - CORPORATION FOR NATIONAL AND COMMUNITY SERVICE. The National and Community Service Act of 1990. Disponível em: <http:/ / www.nationalservice. gov/about/legislation>. Acesso em: 07 jan. 2017.

DAVIS, S. A. et al. Educating sustainable societies for the twenty-first century. International Journal of Sustainability in Higher Education, v.4 n.2, p.169-179, 2003.

DEMAJOROVIC, J.; SILVA, H. C. O. da. Formação interdisciplinar e sustentabilidade em cursos de administração: desafios e perspectivas. RAM, Rev. Adm. Mackenzie, v.13, n.5, set./ out. 2012.

ENGLUND, C.; OLOFSSON, A. D.; PRICE, L. The influence of sociocultural and structural contexts in academic change and development in higher education. High Educ, v.76, p.1051-1069, 2018. 
ERSKINE, L.; JOHNSON, Scott D. Effective Learning Approaches for Sustainability: a Student Perspective. Journal of Education for Business, v. 87, n. 4, p. 198-205, 2012.

FIGUEIRÓ, P. S. Educação para a sustentabilidade em cursos de graduação em administração: Proposta de uma estrutura analítica. Tese de Doutorado, Programa de Pós-Graduação em Administração da Universidade Federal do Rio Grande do Sul, Porto Alegre, RS, 2015.

FIGUEIRÓ, P. S.; NASCIMENTO, L. F. Educação para a Sustentabilidade na Graduação em Administração: proposta de uma estrutura analítica. In: ENCONTRO DE ENSINO E PESQUISA EM ADMINISTRAÇÃO E CONTABILIDADE - EnEPQ, 6, 2018, Porto Alegre.

FIGUEIRÓ, P. S.; RAUFFLET, E. Sustainability in higher education: a systematic review with focus on management education. Journal of Cleaner Production, v.106, p.22-33, 2015.

FRANCO, I. T. et al. A Inserção da Temática de Sustentabilidade na Formação de Futuros Gestores: como os professores se deparam com o assunto? Administração: Ensino e Pesquisa - RAEP, v.16, n.3, p. 571-607, 2015.

GADOTTI, M. A Carta da Terra na Educação. 1. ed. São Paulo: Editora e Livraria Instituto Paulo Freire, 2010, 103p. Disponível em: < http: / / acervo.paulofreire.org:8080/jspui/ bitstream/7891/2812/4/FPF_PTPF_12_048.pdf>. Acesso em: 18 ago. 2017.

GADOTTI, M. Educação para a Sustentabilidade: uma contribuição à Década da Educação para o Desenvolvimento Sustentável. 1a ed. São Paulo: Editora e Livraria Instituto Paulo Freire, 2008. 127 p.

INEP - Instituto Nacional de Estudos e Pesquisas Educacionais Anísio Teixeira. Sinopse Estatística da Educação Superior 2016. Brasília: Inep, 2017. Disponível em: <http: / / portal.inep.gov.br/basica-censo-escolar-sinopse-sinopse>. Acesso em: 12 jan. 2019.

INEP - Instituto Nacional de Estudos e Pesquisas Educacionais Anísio Teixeira. Sinaes: Sistema Nacional de Avaliação da Educação Superior (a). Disponível em: <http: / inep. gov.br/sinaes>. Acesso em 05 fev. 2019.

INEP - Instituto Nacional de Estudos e Pesquisas Educacionais Anísio Teixeira. Instrumento de Avaliação de Cursos de Graduação: presencial e à distância (b). Disponível em: $<$ http://download.inep.gov.br/educacao_superior/avaliacao_cursos_graduacao/instrumentos/2017/curso_reconhecimento.pdf>. Acesso em: 20 mar. 2019.

JABBOUR, C. J. C. Greening of business schools: a systemic view. International Journal of Sustainability in Higher Education, v.11, n.1, p. 49-60, 2010.

KOEHN, P. H.; UITTO, J. I. Evaluating sustainability education: lessons from international development experience. High Educ, v.67, p.621-635, 2014.

KURUCZ, E. C.; COLBERT, B. A.; MARCUS, J. Sustainability as a provocation to rethink management education: Building a progressive educative practice. Management Learning, p.1-21, 2013. 
KUZMA, E. L.; NOVAK, M. A. L.; DOLIVEIRA, S. L. D.; GONZAGA, C. A. M. A inserção da Sustentabilidade na Formação de Administradores. GeAS. Revista de Gestão Ambiental e Sustentabilidade. São Paulo, v. 5, n. 2, p. 146-165, maio/ago. 2016.

LESSA, B. de S.; SPIER, K. F.; NASCIMENTO, L. F. M. Barriers to Sustainability in Management Schools: a bourdieusian explanation. Administração: Ensino e Pesquisa - RAEP, v.19, n.3, p. 555-582, 2018.

MARCON, G. A.; SORIANO-SIERRA, E. J. Etnografia como Estratégia Investigativa da Cultura Organizacional para a Sustentabilidade. RGSA. Revista de Gestão Social e Ambiental. São Paulo, v.11, n.1, p.38-55, 2017.

MEC - Ministério da Educação. Educação Ambiental. Publicações. Diretrizes Curriculares Nacionais para a Educação Ambiental Resolução CNE/CP n 0 02/2012. Disponível em: $<$ http: / / portal.mec.gov.br/index.php?option=com_docman\&view=downloa$\mathrm{d} \&$ alias=16490-res02-05062012-diretrizes-curriculares-educacao-ambiental\&category_ slug=outubro-2014-pdf\&Itemid=30192> . Acesso em: 12 dez. 2016.

MUNCK, L.; SOUZA, R. B. de; ZAGUI, C. A gestão por Competências e sua Relação com Ações Voltadas à Sustentabilidade. REGE - Revista de Gestão. São Paulo, v. 19, n. 3, p. 377-394, jul./ set., 2012. Disponível em: <https: / /www.revistas.usp.br/rege/article/ view/49909> Acesso em: 20 set. 2017.

ONU. Organização das Nações Unidas. Apesar de baixa fertilidade, mundo terá 9,8 bilhões de pessoas em 2050. Disponível em: <https:/ / news.un.org/en/story/2017/06/ 560022-world-population-hit-98-billion-2050-despite-nearly-universal-lower-fertility\#. WUv3anUrJnw>. Acesso em: 22 fev. 2018.

ONU. Organização das Nações Unidas. Agenda 2030 para o Desenvolvimento Sustentável (2015). Disponível em: <https:// nacoesunidas.org/wp-content/uploads/2015/10 / agenda2030-pt-br.pdf $>$. Acesso em: 22 fev. 2018.

PALMA, L. C.; ALVES, N. B.; SILVA, T. N. da. Educação para a sustentabilidade: a construção de caminhos no Instituto Federal de Educação, Ciência e Tecnologia do Rio Grande do Sul (IFRS). RAM, Rev. Adm. Mackenzie, v.14, n.3, Ed. Especial, São Paulo, 2013.

PETARNELLA, L.; SILVEIRA, A.; MACHADO, N. S. Educação Ambiental e Ensino de Sustentabilidade: reflexão no contexto da administração. Revista de Gestão Ambiental e Sustentabilidade - GeAS. São Paulo, v.6, n.1, jan./abr. 2017.

PETRINI, M.; POZZEBON, M. Integrating Sustainability into Business Practices: learning from brazilian firms. BAR. Brazilian Administration Review, v.7, n.4, p.362-378, 2010.

PIDLISNYUK, V. Education in Sustainable Development: the role of universities. Economic and Environmental Studies, v.10, n.1, p.59-70, 2010.

PONTES, A. S. M., et al. Sustentabilidade e Educação Superior: análise das ações de sustentabilidade de duas instituições de ensino superior de Santa Catarina. ReA. Rev. Adm. UFSM, v.8, ed. especial, p. 84-103, 2015. 
PRME. The Principles for Responsible Management Education. Disponível em: <http:/ / www.unprme.org> Acesso em: 01 mar. 2018.

RICHTER, T.; SCHUMACHER, K. P. Who Really Cares About Higher Education For Sustainable Development? Journal of Social Sciences, v.7, n.1, p. 24-32, 2011.

SCHUTEL, S. Aprendizagem Transformadora para o desenvolvimento sustentável futuro: estudo de caso em cursos de administração no Canadá e no Brasil. Tese de Doutorado, Programa de Pós-Graduação em Administração da Universidade Federal do Rio Grande do Sul, Porto Alegre, RS, 2015.

SETÓ-PAMIES, D.; PAPAOIKONOMOU, E. A Multi-level Perspective for the Integration of Ethics, Corporate Social Responsability and Sustainability (ECSRS) in Management Education. Journal of Business Ethics, v.136, p.523-538, 2016.

SHARMA, S.; HART, S. Beyond “Saddle Bag” Sustainability for Business Education. Organization \& Environment, v.27, n.1, p.10-15, 2014.

TASSONE, V. C. (Re-)designing higher education curricula in times of systemic dysfunction: a responsible research and innovation perspective. High Educ, v.76, p.337-352, 2018.

TERCEK, M. R.; ADAMS, J. S. Capital Natural: Como as empresas e a sociedade podem prosperar ao investir no meio ambiente. 1a ed. São Paulo: Editora Alaúde, 2014. 268 p.

THOMAS, I.; HEGARTY, K.; HOLDSWORTH, S. The Education for Sustainability JigSaw Puzzle: Implementation in Universities. Creative Education, v.3, p.840-846, 2012.

UNESCO. Teaching and Learning for a Sustainable Future. Disponível em: $<$ http: / / www.unesco.org/education/tlsf/>. Acesso em: 10 mar 2019.

YIN, R. K. Estudo de Caso: Planejamento e Métodos. 4a ed. Porto Alegre: Editora Artmed, 2010. $248 \mathrm{p}$.

YORIO, P. L.; YE, F. A Meta-Analysis on the Effects of Service-Learning on the Social, Personal, and Cognitive Outcomes of Learning. Academy of Management Learning $\&$ Education, v. 11, n. 1, p. 9-27, 2012. 


\section{DADOS DOS AUTORES}

\section{PAOLA SCHMITT FIGUEIRÓ paolaadm@gmail.com}

Doutora em Administração pela UFRGS

Instituição de vinculação: Universidade Feevale

Novo Hamburgo/RS - Brasil

Áreas de interesse em pesquisa: Educação para a Sustentabilidade, Inovação Social, Negócios de Impacto Social.

ERS 239, 2755 Vila Nova Novo Hamburgo/RS 93525-075

\section{GUILHERME FROZZA FELIX DA SILVA phellycs@gmail.com}

Graduação em Administração pela Universidade Feevale

Instituição de vinculação: Universidade Feevale

Novo Hamburgo/RS - Brasil

Áreas de interesse em pesquisa: Educação para a Sustentabilidade, Diversidade e Inclusão, Negócios de Impacto Social.

\section{ARIANA RAQUEL PHILERENO ariana.philereno@hotmail.com}

Graduação em Administração pela Universidade Feevale

Instituição de vinculação: Universidade Feevale

Novo Hamburgo/RS - Brasil

Áreas de interesse em pesquisa: Educação para a Sustentabilidade, Diversidade e Inclusão, Negócios de Impacto Social. 